Research article

\title{
Changes in anti-viral effectiveness of interferon after dose reduction in chronic hepatitis c patients: a case control study Frank C Bekkering ${ }^{1}$, Avidan U Neumann², Johannes T Brouwer ${ }^{1}$, Rachel S Levi-Drummer ${ }^{2}$ and Solko W Schalm*1
}

Address: ${ }^{1}$ Dept. of Hepatology \& Gastroenterology, University Hospital Rotterdam, the Netherlands and ${ }^{2}$ Faculty of Life Sciences, Bar-Ilan University, Ramat-Gan, Israel

E-mail: Frank C Bekkering - fcbekkering@hotmail.com; Avidan U Neumann - neumann@mail.biu.ac.it; Johannes T Brouwer - brouwer@mdl.azr.nl; Rachel S Levi-Drummer - drummer@mail.biu.ac.it; Solko W Schalm* - schalm@mdl.azr.nl ${ }^{*}$ Corresponding author

Published: 13 December $200 \mid$

BMC Gastroenterology 200 I, I:I4
Received: II October 200 I

Accepted: 13 December 200 I

This article is available from: http://www.biomedcentral.com//47I-230X/I//4

(C) 200 I Bekkering et al; licensee BioMed Central Ltd. Verbatim copying and redistribution of this article are permitted in any medium for any noncommercial purpose, provided this notice is preserved along with the article's original URL. For commercial use, contact info@biomedcentral.com

\begin{abstract}
Background: High dose interferon induction treatment of hepatitis $\mathrm{C}$ viral infection blocks viral production over $95 \%$. Since dose reduction is often performed due to clinical considerations, the effect of dose reduction on hepatitis $C$ virus kinetics was studied.
\end{abstract}

Methods: A new model that allowed longitudinal changes in the parameters of viral dynamics was used in a group of genotype-I patients $(N=15)$ with dose reduction from 10 to 3 million units of interferon daily in combination with ribavirin, in comparison to a control group $(N=9)$ with no dose reduction.

Results: Dose reduction gave rise to a complex viral kinetic pattern, which could be only explained by a decrease in interferon effectiveness in blocking virion production. The benefit of the rapid initial viral decline following the high induction dose is lost after dose reduction. In addition, in some patients also the second phase viral decline slope, which is highly predictive of success of treatment, was impaired by the dose reduction resulting in smaller percentage of viral clearance in the dose reduction group.

Conclusions: These findings, while explaining the failure of many induction schedules, suggest that for genotype-I patients induction therapy should be continued till HCVRNA negativity in serum in order to increase the sustained response rate for chronic hepatitis $C$.

\section{Background}

The hepatitis $\mathrm{C}$ virus (HCV) causes a slowly progressive liver disease, which may lead to cirrhosis, liver failure and liver cancer. Currently, about 10,000 patients die in the US from HCV related disease yearly and this number is expected to triple in the next 2-3 decades [1] Anti-viral therapy is successful in arresting the progression of the disease in those patients who reach a sustained clearance of the virus, currently only $40 \%$ of treated patients [2]. Response to therapy with alpha Interferon injections thrice a week with or without additional Ribavirin is thought to occur gradually over time, and research has focused on improving efficacy by prolonging treatment up to 1 to 2 years [24]. However, reports on viral dynamics analysis show that 
response to interferon is very fast and that a 10 to 1000 fold decrease in viral load can be reached within 24 hours of treatment. [5-7] The pattern of viral decline seems to be biphasic, with a rapid viral decline within the first 2448 hours followed by a much slower second phase of viral decline. This biphasic decline is hypothetically caused by a direct anti-viral effect of interferon in blocking virion production from infected cells [5].

A strong dependence of the viral decline in the first phase on the dose of interferon used has been described $[5,8]$. Nevertheless, it has been shown that it is the second slope which is the best predictor for response to treatment $[5,9]$. This slower second phase slope of viral decline has large variability between patients, and therefore cross sectional analysis of its dose dependence is hindered. Instead, here we investigated the longitudinal changes in viral dynamics in patients going through a dose reduction in order to asses the effect of dose on the second slope. The current model for HCV dynamics, in which the dynamical parameters are fixed during treatment, fits the observed biphasic viral decline in patients treated with fixed Interferon dosages [5]. However, in this study we adapted the model such that the dynamical parameters can change over time due to a change in dose. We now report that early dose reduction is followed by a rise in viral load, that can only be explained by a decrease in interferon effectiveness; so the potential benefit of a rapid viral decline following high dose induction is often lost.

\section{Methods}

A case-control study was performed in an university-based tertiary referral center. Informed consent was obtained from all patients, and the human experimentation guidelines of the University Hospital Rotterdam were followed in the conduct of clinical research.

\section{Study population}

All 24 HCV genotype-1 patients enrolled in our high-dose induction studies were evaluated. All patients met the inclusion and exclusion criteria previously described [10]. Note that all patients in these studies were considered "difficult-to-treat", either because they were non-responders to previous treatment or had cirrhosis and/or high baseline viral load. Group 1 patients $(\mathrm{N}=9)$ received 10 million units $(\mathrm{MU})$ of Interferon- $\alpha-2 b$ (Intron- $A$, Schering-Plough) daily for 4 weeks. Group 2 patients $(\mathrm{N}=15)$ received $10 \mathrm{MU}$ of interferon daily for the first 3 days only, followed by $3 \mathrm{MU}$ interferon daily from day 3 until day 28. In both groups, ribavirin was given orally in divided doses of 1,000-1,200 mg daily (according to weight $>75$ $\mathrm{kg}$ ). Subsequently, all patients received a maintenance treatment of minimally 3 MU interferon daily for 52 weeks. The patients' baseline characteristics (Table 1) were well balanced, except for a trend for larger number of cirrhotic patients in group 1 .
Table I: Patient baseline characteristics.

\begin{tabular}{lcc}
\hline Patient characteristics & Group I (I) & Group 2 (I) \\
\hline Number of patients & 9 & 15 \\
Median age & 44 & 47 \\
Male/Female & $7 / 2$ & $11 / 4$ \\
Race (Caucasian / Asian) & $7 / 2$ & $15 / 0$ \\
Pre-treatment RNA HCV & $5.5 . \times 10^{6}$ & $7.5 \times 10^{6}$ \\
Genotype I & All & All \\
Median ALT at baseline & 89 & 122 \\
Cirrhosis/No-cirrhosis & $4 / 5$ & $1 / 14$ \\
Previous NR / other & $6 / 3$ & $11 / 4$ \\
& & \\
\hline
\end{tabular}

*) Non-sustained responder to previous therapy or previously untreated patients with cirrhosis and genotype I.

\section{Detection of Serum HCV RNA}

Plasma samples were collected frequently during the first 4 weeks of treatment for HCV RNA detection. Blood samples were collected in Vacutainer PPT tubes (Becton-Dickinson) which were spun directly after collection in order to avoid RNA breakdown. The spun PPT tubes [11] were then transported to the virology department where plasma was aliquotted in 5 separate tubes that were stored at $-80^{\circ} \mathrm{C}$. Plasma samples were obtained at day $0(0,4,8,12$, 16 hours), day 1 (24, 32 and 40 hours), day 2 ( 48 and 56 hours), day 3 (72 and 80 hours) day 4, 5, 6 7, 10, 14, 17, 21 and 28 after treatment initiation. Viral load was quantified using the Cobas Amplicor Monitor ${ }^{\mathrm{TM}}$ version 2 (Roche Molecular Systems). Since the linearity of quantitative assays for high numbers of viral copies has been questionable [12] we routinely diluted samples and re-tested, if the early quantification of that sample was higher than $10^{6}$ copies/ml.

\section{Mathematical Modeling}

Viral kinetics were analyzed using a modification of a previously described mathematical model for viral dynamics [5], for which the analytical solution is,

$\mathrm{V}(\mathrm{t})=\mathrm{V}_{0}\left\{\mathrm{~A} \exp \left[-\lambda_{1}\left(\mathrm{t}-\mathrm{t}_{0}\right)\right]+(1-\mathrm{A}) \exp \left[-\lambda_{2}\left(\mathrm{t}-\mathrm{t}_{0}\right)\right]\right\}$ for $\left(\mathrm{t}>\mathrm{t}_{0}\right) \quad$ (Eq. 1$)$

Where

$\lambda_{1,2}=1 / 2\left\{(c+\delta) \pm\left[(c-\delta)^{2}+4(1-\varepsilon)(1-H) c \delta\right]^{1 / 2}\right\}$ (Eq. 2)

$\mathrm{A}=\left(\varepsilon c-\lambda_{2}\right) /\left(\lambda_{1}-\lambda_{2}\right)$

This formula contains several dynamical parameters $(c, \delta$, $H$ and $\varepsilon$ ) which may vary per patient according to the best fit of the actual data, but are constant over time. c de- 
scribes the clearance rate of free virus, with the corresponding virus half-life of $\ln (2) / c$. $\delta$ describes the loss rate of productively infected cells, with the corresponding cellular half-life of $\ln (2) / \delta$. The effect of interferon can be modeled here either by a block of de-novo cell infection with effectiveness $\mathrm{H}(0 \leq \mathrm{H} \leq 1)$, or block of virion production with effectiveness $\varepsilon(0 \leq \varepsilon \leq 1)$. The logarithmic drop in viral decline during the first phase (24-48 hours) of treatment can be approximated by $\log (1-\varepsilon)$. The $2^{\text {nd }}$ phase slope can be approximated by $\varepsilon$ times $\delta$ when $H \ll 1$, or by $\delta$ alone when $\mathrm{H} \cong 1$.

To investigate the effect of reducing treatment dose, all the above dynamical parameters were allowed to change over time in the solution, e.g. for interferon effectiveness in blocking virion production, $\varepsilon$, we use the function $\varepsilon(\mathrm{t})$ :

$$
\begin{aligned}
& \text { for } \mathrm{t} \leq \mathrm{t}_{1}: \varepsilon(\mathrm{t})=\varepsilon_{1} \\
& \text { for } \mathrm{t}>\mathrm{t}_{1}: \varepsilon(\mathrm{t})=\left(\varepsilon_{1}-\varepsilon_{2}\right) \exp \left(-\mathrm{k}\left(\mathrm{t}-\mathrm{t}_{1}\right)\right)+\varepsilon_{2}
\end{aligned}
$$

where $t_{1}$ is the time of dose change and $\mathrm{k}$ is a exponential rate representing how rapid does the change in interferon dose effect the change in the parameter. Thus, the blocking effectiveness starts at $\varepsilon_{1}$ (for $\mathrm{t} \leq \mathrm{t}_{1}$ ), and changes with an exponential transition to $\varepsilon_{2}\left(\right.$ after $\left.\left(t-t_{1}\right)>>1 / k\right)$. The same functional form was used to investigate changes in $\mathrm{H}$ (from $\mathrm{H}_{1}$ to $\mathrm{H}_{2}$ ), $\delta$ (from $\delta_{1}$ to $\delta_{2}$ ), and c (from $\mathrm{c}_{1}$ to $\mathrm{c}_{2}$ ).

It is important to note that we do not explicitly model in Eq. 1 the dynamics of viral replication after the dose reduction, but rather replace the fixed parameters by time dependent parameters in the original analytical solution obtained with fixed parameters. Nevertheless, we have tested this approximation by simulating a modification of the original differential equation model [5] where changes in the dynamical parameters were allowed to change at the time of dose reduction. We found no significant difference between the simulation of the full modified differential equation model and the modified analytical solution. Since we only have $2-3$ viral measurements immediately after dose reduction, we can not estimate the appropriate replication parameters and thus chose to use the simple approximation given in Eq 1 .

To estimate HCV viral kinetic parameters for each patient, the logarithm of $V(t)$ in Eq. 1 (using $\varepsilon(t)$ from Eq. 4) was fit to the logarithm of the viral load data by a non-linear least squares method using the Madonna software (R.I. Macey and G.F. Oster, Berkeley, CA, USA). Two patients in group 2 were missing viral load data during the first week of treatment and one patient had a null response (less than 3 fold change in viral load during treatment) and therefore their viral kinetics could not be fitted.

\section{Statistical analysis}

The Fisher-exact test $(2 \times 2$ tables $)$ and the Chi-square test $(\mathrm{N} \times \mathrm{N}$ tables) were used to determine the statistical significance of the distribution of categorical variables between groups. The non-parametric independent (or related) Mann-Whitney rank sum test was used to determine the statistical significance of differences in continuous variables between the two groups (or of changes in the parameters within the same patients). Correlation among parameters, or between parameters and baseline values, was evaluated using the Spearman non-parametric test. Significance was established at $\mathrm{P}<0.05$.

\section{Results}

The biphasic decline previously reported $[5-7,13]$ describes the viral kinetics during the first month for all patients in group 1 (Fig 1, Fig 2a), for whom interferon dose was kept constant. In contrast, we observed a complex dynamic pattern for 11 out of 12 evaluable patients in group 2 (Fig 1, Fig 2b,c,d). In these patients, a rapid decline occurred during the first day, followed by a slower decline on the second and third days, at which point a rapid increase in viral load (mean 0.8 [range 0-1.3] log copies/ $\mathrm{ml}$ ) is observed within $24-48$ hours after the reduction in interferon dose. Thereafter, viral load again declined with a mean exponential slope comparable to the second phase slope in group 1 .

We have tried to fit the viral kinetics of the patients in group 2 with several models, in each one of them allowing to change one parameter $(\varepsilon, \mathrm{H}, \mathrm{c}$ or $\delta)$ at the time of dose reduction. The only model that was able to qualitatively reproduce the observed kinetics was the one which allowed a longitudinal change in the interferon effectiveness in blocking virion production $(\varepsilon)$ as function of the interferon dose (Eq. 4). By only allowing to change the interferon effectiveness in blocking de-novo infection $(\mathrm{H})$, death rate of infected cells $(\delta)$ or the clearance rate of free virions (c), it was not possible to fit the observed data. When assuming the major effect of interferon is to block virion production in a dose dependent way $\left(1>\varepsilon_{1}>\varepsilon_{2}>\right.$ $0)$, it was possible to fit the data both with $\mathrm{H}=0$ or $\mathrm{H}=1$. Thus it was not possible to determine if interferon also blocks de-novo infection, in addition to blocking virion production, or not. Varying $\mathrm{H}$ between 0 and 1 only gives rise to minimal changes in the estimate of $\varepsilon$ and $c$, while somewhat affecting the estimate of $\delta$ when $\varepsilon$ is smaller than 0.98 (minimal estimate of $\delta$ obtained for $\mathrm{H}=1$, and maximal estimate for $\mathrm{H}=0$ ). Moreover, when allowing $\varepsilon$ to change at the time of dose reduction, it was not possible to rule out that the other parameters also change at the same time.

For simplicity, and since our data only implies minute effects due to changes in the other parameters, we have as- 


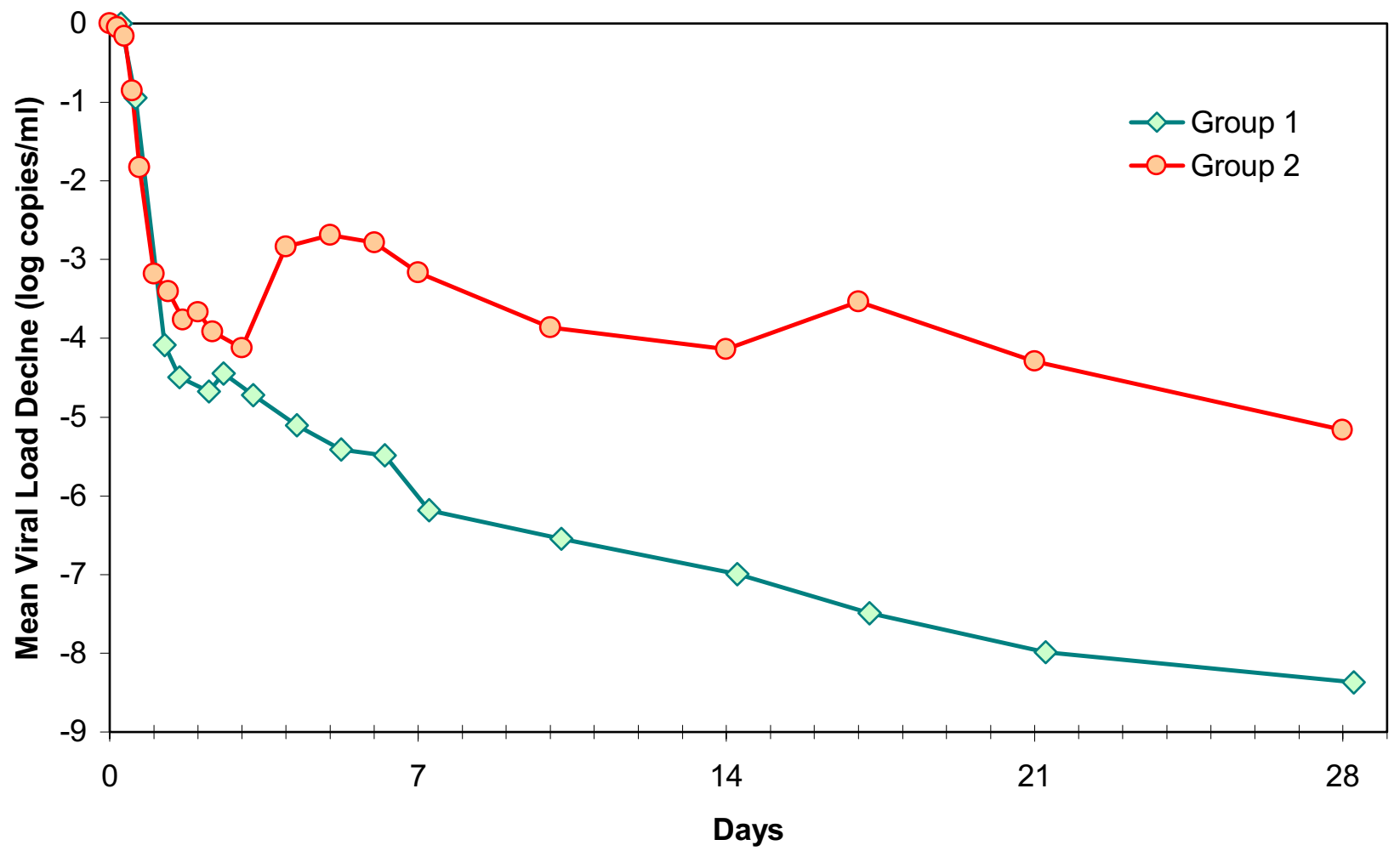

Figure I

Group I $(\mathrm{N}=9$ ) received a continues dose of $10 \mathrm{MU}$ INTERFERON daily for 28 days. Group 2 (dose reduction group, $\mathrm{N}=15$ ) reduced from 10 MU INTERFERON daily to 3 MU INTERFERON daily after 3 days of treatment. After the viral load data was log-transformed, the geometric means were calculated for the 2 groups for each time-point of viral load measurement. The created mean viral for group I clearly shows a biphasic decline in viral load as previously described for chronic HCV. Viral decline in the patients with a INTERFERON dose reduction (line Group 2) is more complex: a rebound in viral load is observed coinciding with the time of INTERFERON dose reduction.

sumed a change occurs only in $\varepsilon$ when estimating the dynamical parameters. In addition, we needed to estimate the transition rate $\mathrm{k}$ (Eq. 4) from $\varepsilon_{1}$ to $\varepsilon_{2}$. It was not possible to get a unique estimate of $\mathrm{k}$ for each patient individually, with only 2-3 measurements during the rebound. Since using $\mathrm{k}=1 \mathrm{up}$ to 20 did not significantly affect the estimate of the other parameters, we have assumed $\mathrm{k}=2$ for all patients such that the effect of $\varepsilon_{1}$ vanishes within 24-48 hours after the dose reduction in accordance to the observed data.

The estimates obtained by non-linear fitting of each patient's viral kinetics individually are given in Table 2. As expected the baseline viral load, the half-life of free virions and the initial effectiveness in blocking virion production, all related to the first phase decline, were similar between the 2 groups. Mean half-life of free virions for all patients was 3.0 hours \pm standard deviation of 1.6 hours, similar to that derived in previous studies for interferon- $\alpha$ monotherapy (2.7 hours) [5]. The mean effectiveness in blocking virion production for all patients was $95.6 \% \pm 6.5 \%$ for the $10 \mathrm{MU}$ interferon dose. For group 1 the non-linear fit (with Eq. 4) did not give rise to a significant change in $\varepsilon$ over time, in accordance to the constant daily interferon dose used in these patients (insert Fig 2a). For group 2, however, a significant $(\mathrm{p}<0.005)$ decrease in effectiveness of blocking production was observed (inserts Fig $2 b, c, d$, 

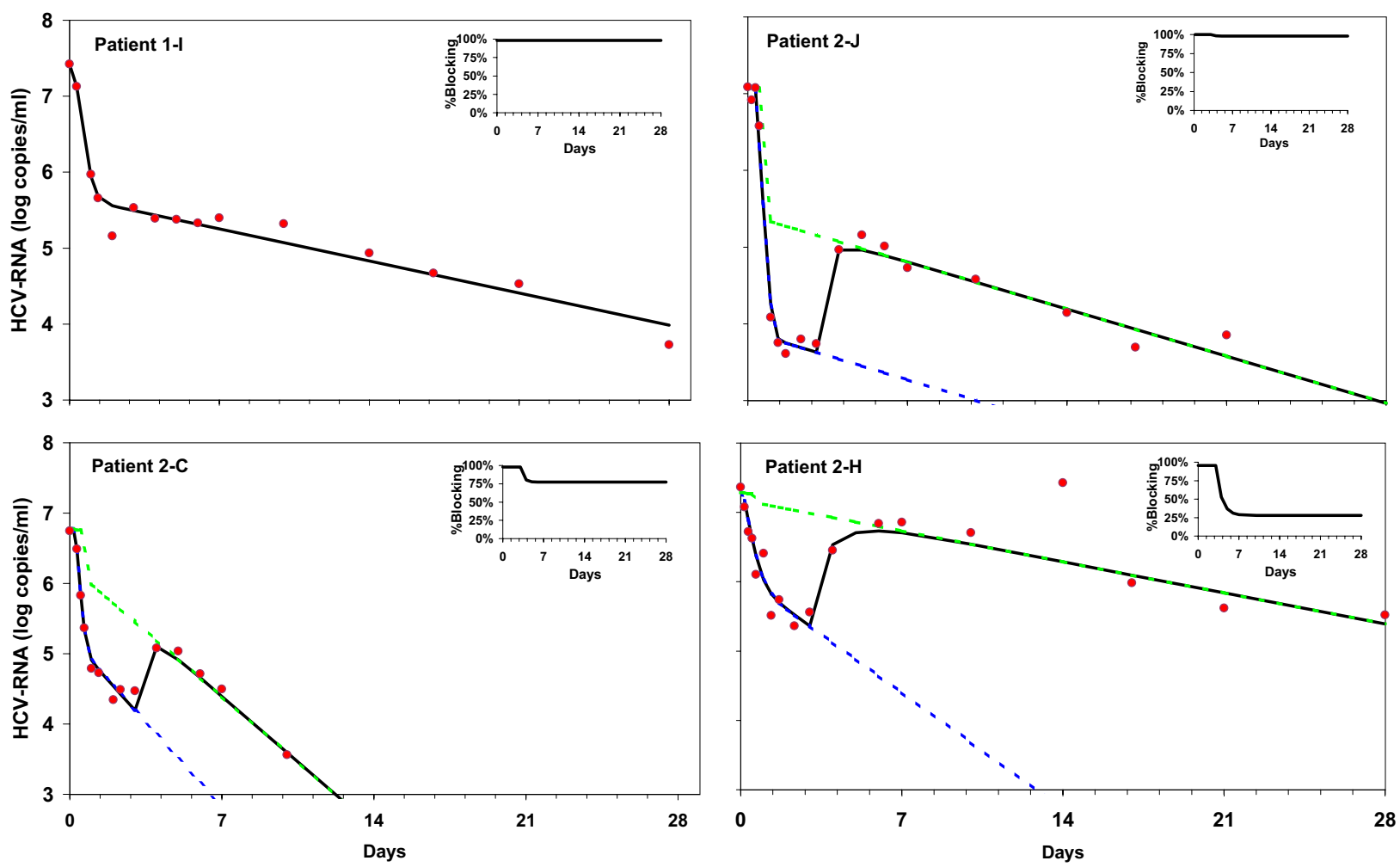

\section{Figure 2}

In figure $2 \mathrm{a}$ the actual viral load measurements (red dots) and the fitted viral decline curve using Eq. I (black line) is presented of one of the patients (No I-I) who receive 10 MU INTERFERON daily for 28 days. The actual decline in viral load in this patient is best described by the original bi-phasic model. In figure $2 b, c, d$ the actual viral load (red dots) and the fitted viral decline using the modified model allowing for a change in INTERFERON efficacy as described in Eq.5 is presented (black line). The actual viral decline could only be correctly fitted by using our modified model. The red lines represent the calculated biphasic decline curve for a continues 10 MU INTERFERON regimen in the patients of group 2 by fitting only the observed viral load during the treatment period of $10 \mathrm{MU}$ daily in the original model. The green line represents the calculated viral decline curve as if a continues treatment of 3 MU INTERFERON daily was given from the start of treatment (only the viral load during $3 \mathrm{MU}$ INTERFERON are fitted). Note that the difference in the slope between the calculated decline curves for $10 \mathrm{MU}$ versus $3 \mathrm{MU}$ (red versus green lines) is dependent on the change in interferon efficacy after dose reduction (inserts). Patients 2- $\mathrm{H}$ was calculated to become HCV RNA negative within 14 days if 10 MU INTERFERON was continued (red line figure 2-d), but after dose reduction the actual viral decline curved shifted dramatically due to a strong decline in INTERFERON efficacy (green line).

Fig 3a) from an average of $\varepsilon_{1}=94 \% \pm 8 \%$ to $\varepsilon_{2}=69 \% \pm$ $27 \%$. The effectiveness of interferon with $10 \mathrm{MU}\left(\varepsilon_{1}\right)$ and with $3 \mathrm{MU}\left(\varepsilon_{2}\right)$ were pair wise correlated $(\mathrm{R}=0.8, \mathrm{P}<$ $0.001)$.

Cross-sectionally there was no difference observed between the 2 groups in the death rate of infected cells (Table 2 ) or in the second phase slope (Fig 3b). However, longitudinal analysis of group 2 patients revealed a significant decrease from the predicted second phase slope, which would have occurred without a dose reduction, to the actual slope after dose reduction in 4 out of 12 pa- tients (Fig 4a). These are the patients with the largest decrease (range $20 \%$ to $68 \%$ ) from $\varepsilon_{1}$ to $\varepsilon_{2}$, since the second slope is a linear function of the interferon effectiveness in blocking production $(\varepsilon)$.

The clinical consequences of the viral dynamics data relate to the predicted time of HCV RNA negativity, which is strongly dependent on the second phase slope. The predicted time to $\mathrm{HCV}$-negativity with the biphasic model (median 3.5 weeks) was confirmed by the observed individual data of group 1 patients (median 4 weeks), and the dose-reduction model (with the reduced 3 MU dose) pre- 


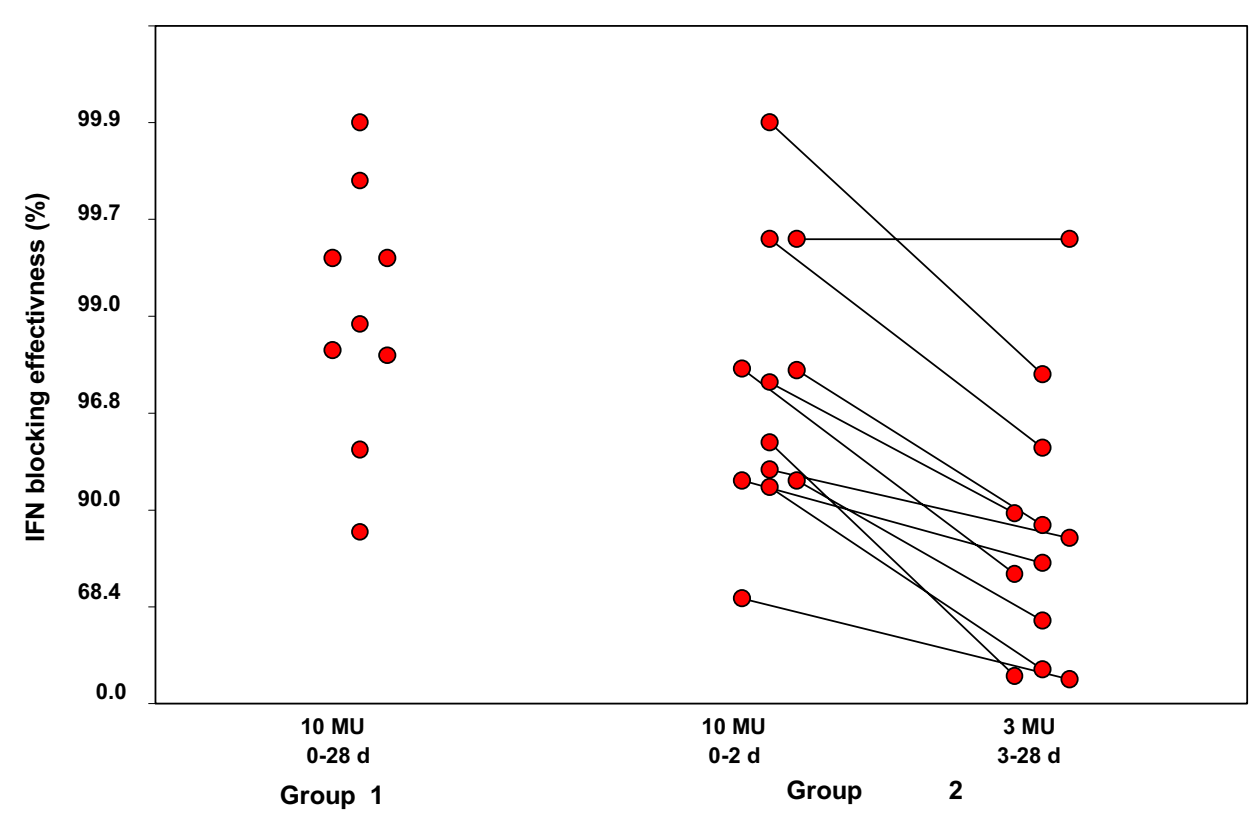

Figure 3b:

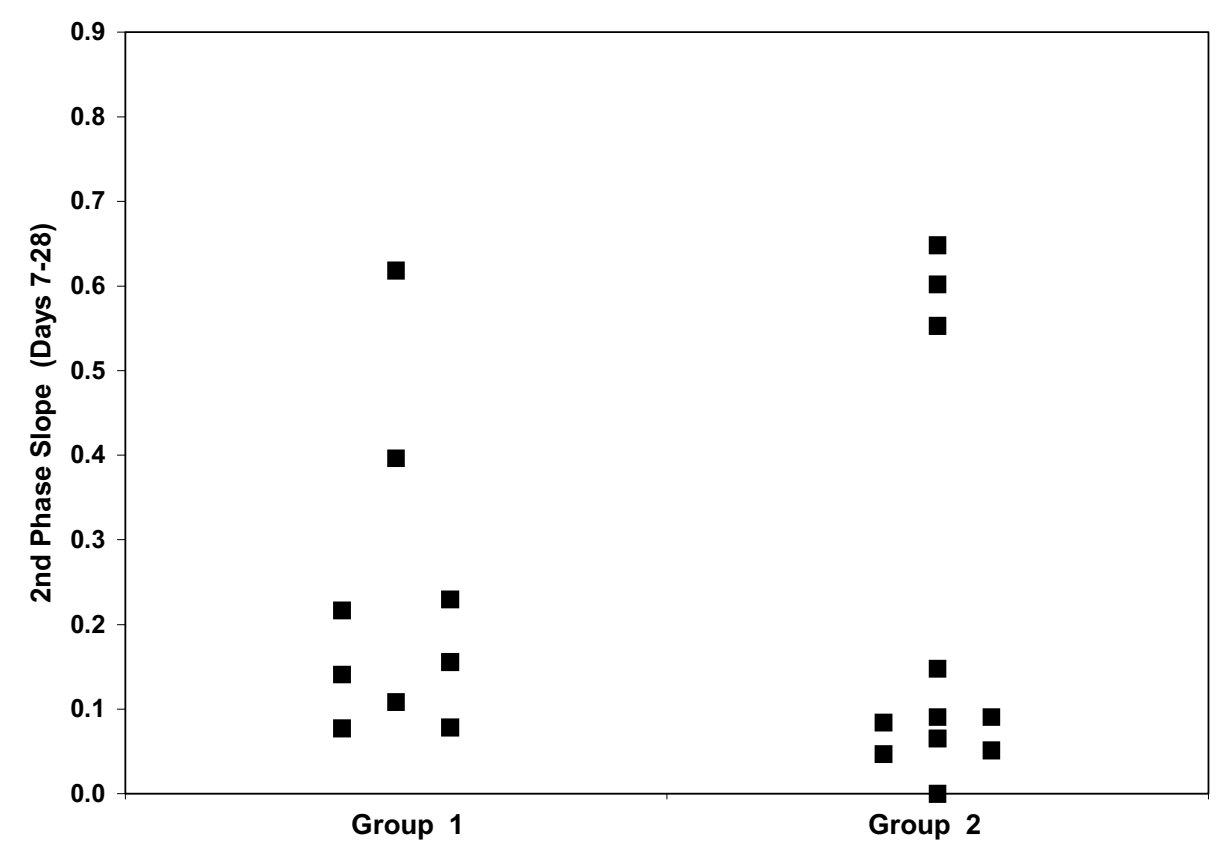

Figure 3

Figure 3a. Interferon efficacy in blocking production (\%) is displayed for group I and group 2 (logarithmic scale). For the patients that received a dose reduction after 3 days of treatment (group 2), both the efficacy for the initial, I0 MU INTERFERON daily period, is displayed as well as the reduced efficacy after the dose reduction to 3 MU daily. Note that the initial interferon efficacy between group I and 2 does not differ. After the dose reduction the interferon efficacy is reduced in II/I 2 patients in group 2 (connected black dots). Figure $3 b$. The slopes of the second phase decline (days ${ }^{-1}$ ) is represented per patient (black squares) for both groups. No differences between both groups could be observed in this study. 
Table 2: Results of non-linear fitting of viral dynamics

\begin{tabular}{|c|c|c|c|c|c|}
\hline \multirow[t]{2}{*}{ Patient $(\mathrm{I})$} & \multirow[t]{2}{*}{ Initial viral load (log copies/ml) } & \multicolumn{2}{|c|}{ \% blocking production } & \multirow{2}{*}{$\begin{array}{l}\text { Half-life(2) of } \\
\text { free virions } \\
\text { (hours) }\end{array}$} & \multirow{2}{*}{$\begin{array}{c}\text { Half-life of infected } \\
\text { cells (days) } \\
\text { minimal and maximal } \\
\text { estimates }(3)\end{array}$} \\
\hline & & During $10 \mathrm{MU}$ qd & After reduction to $3 \mathrm{MU}$ qd & & \\
\hline I-A & 6.9 & 98.4 & & 2.3 & $8.7-8.8$ \\
\hline I-B & 6.9 & 99.9 & & 2.5 & $3.0-3.0$ \\
\hline $\mathrm{I}-\mathrm{C}$ & 6.7 & 99.5 & & 2.2 & $1.7-1.7$ \\
\hline I-D & 6.1 & 86.9 & & 1.9 & $7.8-9.0$ \\
\hline I-E & 5.8 & 99.5 & & 5.3 & $4.4-4.5$ \\
\hline $\mathrm{I}-\mathrm{F}$ & 6.4 & 98.5 & & 6.4 & $3.2-3.2$ \\
\hline I-G & 7.0 & 95.1 & & 1.8 & $6.1-6.4$ \\
\hline $\mathrm{I}-\mathrm{H}$ & 7.1 & 99.8 & & 1.7 & $1.1-1.1$ \\
\hline $1-1$ & 7.4 & 98.9 & & 3.3 & $4.9-4.9$ \\
\hline Group I(4) mean (std) & $6.7(0.5)$ & $97.4 \%(0.04)$ & & 3.0 hours $(1.7)$ & $4.5-4.7$ days $(2.6-2.8)$ \\
\hline $2-A$ & 7.3 & 93.0 & 62.5 & 1.8 & $4.8-7.7$ \\
\hline $2-C$ & 6.8 & 98.1 & 78.5 & 3.3 & $0.9-1.2$ \\
\hline $2-E$ & 6.7 & 93.8 & 86.0 & 3.3 & $7.1-8.2$ \\
\hline $2-\mathrm{F}$ & 6.5 & 99.6 & 95.2 & 1.9 & $1.0-1.0$ \\
\hline $2-G$ & 7.2 & 97.8 & 85.0 & 3.3 & $4.0-4.7$ \\
\hline $2-\mathrm{H}$ & 7.3 & 95.5 & 27.8 & 3.9 & I.2-4.7 \\
\hline $2-1$ & 6.1 & 98.1 & 88.0 & 1.1 & $11.8-13.5$ \\
\hline $2-J$ & 7.1 & 99.9 & 98.0 & 1.6 & $3.4-3.4$ \\
\hline $2-K$ & 7.1 & 71.4 & 25.2 & 2.1 & $2.6-2.7$ \\
\hline $2-L$ & 6.3 & 99.6 & 99.6 & 6.9 & $2.2-2.3$ \\
\hline $2-M$ & 7.4 & 93.0 & 81.1 & 2.1 & $12.0-14.8$ \\
\hline $2-N$ & 6.8 & 92.4 & 33.2 & 3.6 & $2.5-7.7$ \\
\hline Group $2^{(4)}$ mean (std) & $6.9(0.4)$ & $94.3 \%(0.08)$ & $69.1 \%\left(^{* *}\right)(26.6)$ & 2.9 hours $(1.6)$ & $4.4-6.7$ days $(3.9-4.6)$ \\
\hline
\end{tabular}

I) Fitting was not done for: patients 2-B (non-detectable at day 2 on), 2-D (Null-response), 2-O (missing data and rebound). 2) For group I half-life of free virions is only a maximal estimate because only samples from 0,8 and 24 hours were available. 3) Minimal and maximal estimates of the halflife of infected cells was estimated assuming $\mathrm{H}=\mathrm{I}$ and $\mathrm{H}=0$ respectively in Eq 2. 4) No statistically significant differences in any parameter between the two groups. $\left.{ }^{* *}\right)$ Statistically significant $(\mathrm{p}<0.002)$ difference in percentage blocking production before and after dose reduction in group 2.

dicted the time to HCV-negativity in group 2 patients (medians 12 and 14.5 weeks, Table 3). Reducing the interferon dose to $3 \mathrm{MU}$ daily decreased the predicted number of patients that would become HCV-negative within 12 weeks from 12/15 with the $10 \mathrm{MU}$ dose to only $7 / 15$ with the reduced $3 \mathrm{MU}$ dose, as indeed confirmed by the actual individual data $(8 / 15)$.

\section{Discussion}

Our results indicate that the effect of interferon dose reduction on viral dynamics can be completely attributed to decrease in the effectiveness of interferon in blocking vir- ion production $(\varepsilon)$. Changes in other parameters, such as blocking de-novo infection $(\mathrm{H})$ loss rate of infected cells $(\delta)$ and clearance rate of free virions (c), without a change in blocking production, can not reproduce the observed kinetics. The longitudinal dose dependence of the interferon anti-viral effectiveness observed here corroborates the dose dependence of interferon effectiveness previously described only cross-sectionally [5]. The strength of the current results is that the dose dependence of the effectiveness cannot be attributed to baseline differences between the patients. Since longitudinal changes in the other parameters of this model (such as $\mathrm{H}, \delta$ and c) do not give rise 


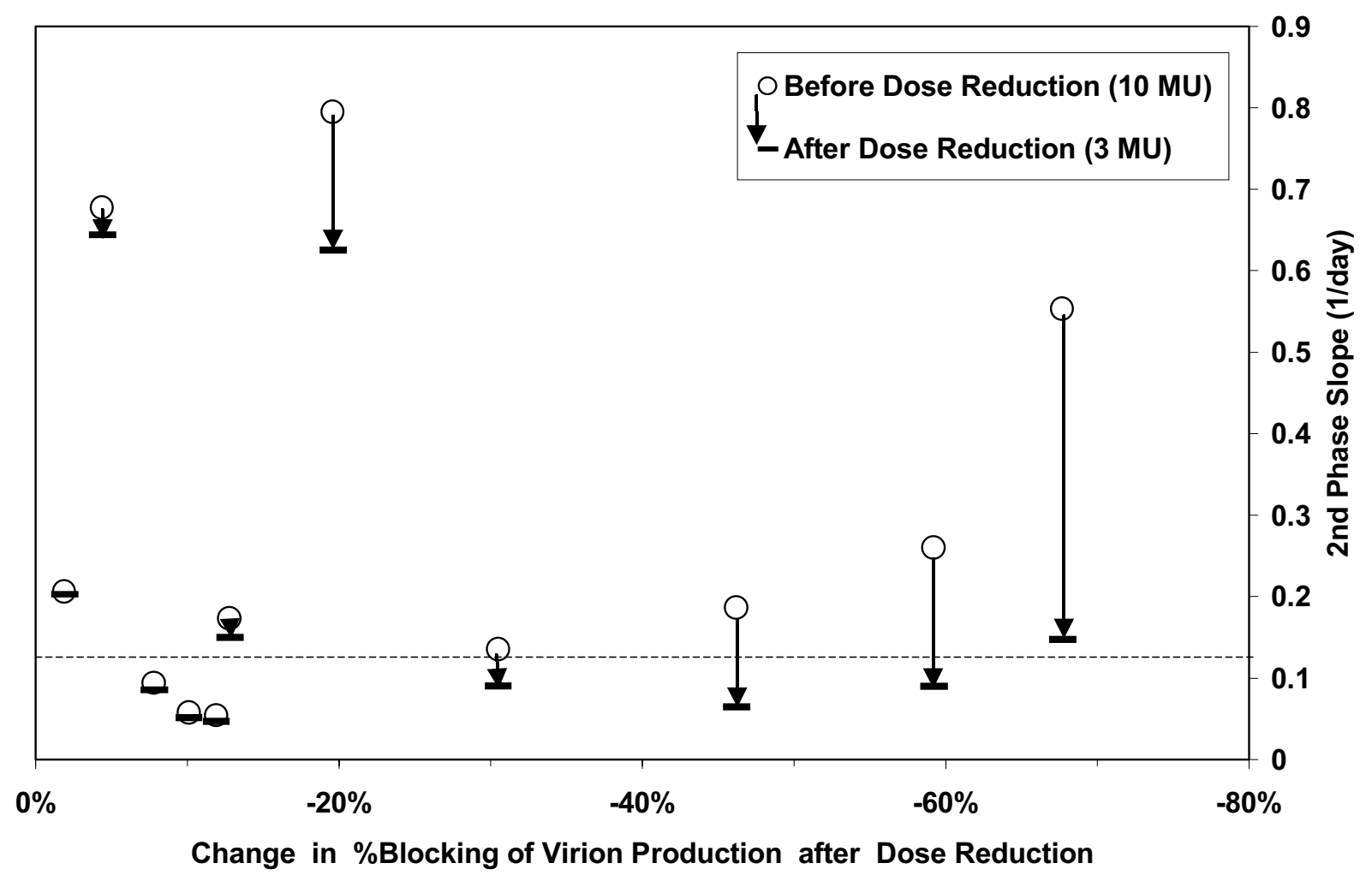

\section{Figure 4}

The effect of the change in interferon efficacy after the dose reduction (x-axis) for the patients in group 2 is related to the change in slope of the second phase viral decline (open circles: second phase slope before dose reduction; horizontal lines: second phase slope after dose reduction). In 4 patients the slope of the second phase reduces drastically, note that 3/4 of these patients have the largest reduction in interferon efficacy. The dashed line reflects the threshold of 0.13 days $s^{-1}$ below which no sustained response was observed.

to significant differences in the kinetics, we can not rule out combined effects of changes in the other parameters concomitantly with the change in effectiveness of blocking production $(\varepsilon)$.

In turn, the dose dependency of the interferon effectiveness determines the result of both the $1^{\text {st }}$ phase and the $2^{\text {nd }}$ phase kinetics. The effectiveness in blocking virion production with $10 \mathrm{MU}$ before dose reduction (mean $95.6 \%$ and a mean viral decline of $1.8 \log \mathrm{cp} / \mathrm{ml}$ ) was similar to that of a previous study with $10 \mathrm{MU}$ interferon (96\%) [5]. However, we show that the benefit of the initial viral decline due to 3 days of high induction dose was lost after the dose reduction in almost all patients (Fig 1, 3 ). The effectiveness in blocking virion production with 3
MU after the dose reduction (mean $69.1 \%$ and a mean viral decline of $0.7 \log \mathrm{cp} / \mathrm{ml}$ ) was similar to that estimated in a previous study with $3 \mathrm{MU}$ interferon initially (70\%) [8]. As a consequence, the viral kinetics after the dose reduction in group 2 patients is similar to the kinetics that would have been obtained if the patients had started with the reduced dose to begin with (green line Fig 2).

In contrast to the $1^{\text {st }}$ phase viral decline, which exponentially depends on the interferon effectiveness, the $2^{\text {nd }}$ phase slope is a linear function of the effectiveness in blocking virion production. This slope is the most predictive parameter for treatment outcome, with a threshold of 0.13 days $^{-1}$ below which no sustained response was observed [5] While the increase observed in viral load imme- 
Table 3: Predicted and observed time to HCV RNA negativity

\begin{tabular}{lccc}
\hline Patient & $\begin{array}{c}\text { Predicted time (weeks) to HCV RNA negativity(I) } \\
\text { with I O MU/daily }\end{array}$ & $\begin{array}{c}\text { Predicted time (weeks) to HCV RNA } \\
\text { negativity(I) with 3 MU/daily }\end{array}$ & $\begin{array}{c}\text { First observedHCV RNA neg- } \\
\text { ativity (I) (weeks) }\end{array}$ \\
\hline I-A & 11 & $12(2)$ \\
I-B & 2 & 2 \\
I-C & 1.5 & 2 \\
I-D & 12 & $4-8$ \\
I-E & 2.5 & 2 \\
I-F & 3.5 & 4 \\
I-G & 10.5 & $4-8$ \\
I-H & 1 & I \\
I-I & 9 & Positive at 24 weeks (3)(4)
\end{tabular}

$\begin{array}{lll}\text { Group I: HCV neg } & 9 / 9 \text { patients } & 8 / 9 \text { patients } \\ \text { before } 12 \text { weeks } & \end{array}$

\begin{tabular}{|c|c|c|c|}
\hline $2-A$ & 9 & 16 & Positive at 24 weeks (3) \\
\hline $2-B$ & I & 1 & 1 \\
\hline $2-C$ & I & 2 & 1.5 \\
\hline 2-D & Never & Never & Positive at 24 weeks (3) \\
\hline $2-E$ & 11 & 13 & $4-8$ \\
\hline $2-\mathrm{F}$ & I & 1.5 & 1.5 \\
\hline 2-G & 5.5 & 7 & $4-8$ \\
\hline $2-\mathrm{H}$ & 3 & 10 & $12-16$ \\
\hline $2-1$ & 11 & 18 & Positive at 24 weeks (3) \\
\hline $2-J$ & 3 & 5 & 4 \\
\hline $2-K$ & 7.5 & 24 & Positive at 24 weeks (3) \\
\hline $2-L$ & 1.5 & 1.5 & 1.5 \\
\hline $2-M$ & 23 & 30 & $8-12$ \\
\hline $2-N$ & 4 & 16 & Positive at 24 weeks (3) \\
\hline $2-0$ & Never & Never & Positive at 24 weeks (3) \\
\hline $\begin{array}{l}\text { Group 2: HCV neg } \\
\text { before } 12 \text { weeks }\end{array}$ & $12 / 15$ patients & $7 / 15$ patients & $8 / 15$ patients \\
\hline
\end{tabular}

Detection level for HCV RNA negativity is at $<500$ copies/ml. 2) Patient I-D had a viral breakthrough after 12 weeks and was HCV RNA positive at 24 weeks of treatment. 3) Patients with positive HCV RNA at 24 weeks stopped treatment according to protocol. 4) Patient I-I was non-compliant from 8 weeks on according to self-report

diately after dose reduction can delay the time to negativity by several weeks at the most (patients 2-J and 2$C$ Fig 2), the decrease in the second phase slope can radically reduce the chance for HCV-RNA negativity (patient $2-\mathrm{H}$ Fig 2). Therefore the decrease in the second slope could be crucial for their success of treatment. Indeed, the number of patients predicted to become HCV-negative within 12 weeks with the high induction dose was drastically reduced due to the dose reduction (compare the 10 MU column versus 3 MU column in Table 3).

Interestingly, the results obtained here are for interferon and ribavirin combination treatment, while the results from previous studies $[5,8]$ are for interferon monotherapy. On the other hand, in this study most patients are non-responders or cirrhotic rather than normal naïve patients as in the previous studies $[5,8]$. Thus, we can not conclude if ribavirin has an additive effect on initial viral decline or not.

Is induction treatment beneficial at all considering that following dose reduction the virus rebounds back to the level it would reach anyway with the reduced dose? Previous studies with a longer period of induction treatment (14 days) do not show a consistent viral rebound as observed here [14]. Moreover, studies of prolonged induction treatment ( $>28$ days) do not show any re-emergence of virus production [15]. Therefore, it could be suggested that an induction period of 3 days is too short, but longer induction periods, which continue until HCVRNA nega- 
tivity in serum, might give rise to continuous suppression of viral replication. In all likelihood this concept may partly explain the increased efficacy of pegylated interferon $[16,17]$ since the rather constant interferon levels with this type of interferon result in a constant block of virus production.

\section{Conclusions}

Dose reduction to $3 \mathrm{MU}$ daily after 3 days of $10 \mathrm{MU}$ of interferon daily in HCV genotype-1 patients negated the extra virus suppressive effectiveness of the induction dose. These observations, while explaining the failure of many induction schedules suggests that induction therapy should be continued till HCV RNA negativity in serum in order to increase the sustained response rate in chronic hepatitis C.

\section{Competing interests}

Frank Bekkering: none declared

Avidan Neumann: none declared

Johannes Brouwer: received grant support from Schering Plough International

\section{Rachel Levi-Drummer: none declared}

Solko Schalm: received grant support from Schering Plough International

\section{Acknowledgments}

We thank Dr. Raj Reddy for fruitful discussions.

Presented in part: $5 \mathrm{I}$ st annual meeting of the American Association for the Study of Liver Diseases, Dallas, 27-3 I October 2000 (Bekkering FC, Neumann AU, Levi-Drummer R, Brouwer JT, Schalm. SW. In-vivo longitudinal changes in anti-viral effectiveness of interferon after dose reduction in chronic hepatitis C patients. Hepatology 2000;32:367A).

Financial support: Schering Plough International, Kenilworth, NJ.

\section{References}

I. Alter MJ: Epidemiology of hepatitis C. Hepatology 1997, 26:62S$65 \mathrm{~S}$

2. McHutchison JG, Gordon SC, Schiff ER, Shiffman ML, Lee WM, Rustgi VK, Goodman ZD, Ling MH, Cort S, Albrecht JK: Interferon alfa$2 \mathrm{~b}$ alone or in combination with ribavirin as initial treatment for chronic hepatitis C. Hepatitis Interventional Therapy Group. N Engl ] Med I998, 339:1485-1492

3. Lin R, Roach E, Zimmerman M, Strasser S, Farrell GC: Interferon alfa-2b for chronic hepatitis $C$ : effects of dose increment and duration of treatment on response rates. Results of the first multicentre Australian trial. Australia Hepatitis C Study Group. J Hepatol 1995, 23:487-496

4. Poynard T, Marcellin P, Lee SS, Niederau C, Minuk GS, Ideo G, Bain V, Heathcote J, Zeuzem S, Trepo C, Albrecht J: Randomised trial of interferon alpha2b plus ribavirin for 48 weeks or for 24 weeks versus interferon alpha2b plus placebo for 48 weeks for treatment of chronic infection with hepatitis $\mathbf{C}$ virus. International Hepatitis Interventional Therapy Group (IHIT). Lancet 1998, 352:1426-1432

5. Neumann AU, Lam NP, Dahari H, Gretch DR, Wiley TE, Layden T], Perelson AS: Hepatitis $\mathbf{C}$ viral dynamics in vivo and the antivi-

ral efficacy of interferon-alpha therapy. Science 1998, 282:103107

6. Bekkering FC, Brouwer JT, Leroux-Roels G, Van Vlierberghe H, Elewaut $A$, Schalm SW: Ultrarapid hepatitis $C$ virus clearance by daily high-dose interferon in non-responders to standard therapy.J Hepatol 1998, 28:960-964

7. Zeuzem S, Schmidt JM, Lee JH, Ruster B, Roth WK: Effect of interferon alfa on the dynamics of hepatitis $C$ virus turnover in vivo. Hepatology 1996, 23:366-37|

8. Lam NP, Neumann AU, Gretch DR, Wiley TE, Perelson AS, Layden TJ: Dose-dependent acute clearance of hepatitis $C$ genotype I virus with interferon alfa. Hepatology |997, 26:226-23|

9. Bekkering FC, Stalgis C, McHutchison JG, Brouwer JT, Perelson AS: Estimation of early hepatitis $C$ viral clearance in patients receiving daily interferon and ribavirin therapy using a mathematical model. Hepatology 200I, 33:419-423

10. Brouwer JT, Nevens F, Kleter B, Elewaut A, Adler M, Brenard R, Chamuleau RA, Michielsen PP, Pirotte J, Hautekeete ML, Weber J, Bourgeois N, Hansen BE, Bronkhorst CM, ten Kate FJ, Heijtink RA, Fevery J, Schalm SW: Efficacy of interferon dose and prediction of response in chronic hepatitis C: Benelux study in 336 patients. J Hepatol 1998, 28:951-959

II. Holodniy M, Mole L, Yen-Lieberman B, Margolis D, Starkey C, Carroll R, Spahlinger T, Todd J, Jackson JB: Comparative stabilities of quantitative human immunodeficiency virus RNA in plasma from samples collected in VACUTAINER CPT, VACUTAINER PPT, and standard VACUTAINER tubes. J Clin Microbiol 1995, 33:1562-1566

12. Mellor J, Hawkins A, Simmonds P: Genotype dependence of hepatitis $C$ virus load measurement in commercially available quantitative assays. / Clin Microbiol I 999, 37:2525-2532

13. Zeuzem S, Lee JH, Franke A, Ruster B, Prummer O, Herrmann G, Roth WK: Quantification of the initial decline of serum hepatitis C virus RNA and response to interferon alfa. Hepatology 1998, 27:1।49-1I56

14. lino S, Hino K, Kuroki T, Suzuki H, Yamamoto S: Treatment of chronic hepatitis $\mathbf{C}$ with high-dose interferon alpha-2b. A multicenter study. Dig Dis Sci 1993, 38:612-618

15. Bekkering FC, Brouwer JT, Hansen BE, Schalm SW: Hepatitis C viral kinetics in difficult to treat patients receiving high dose interferon and ribavirin. J Hepatol 200I, 34:435-440

16. Zeuzem S, Feinman SV, Rasenack J, Heathcote EJ, Lai MY, Gane E, O'Grady J, Reichen J, Diago M, Lin A, Hoffman J, Brunda MJ: Peginterferon alfa-2a in patients with chronic hepatitis $C . N$ Engl I Med 2000, 343:1666-1672

17. Heathcote EJ, Shiffman ML, Cooksley WG, Dusheiko GM, Lee SS, Balart L, Reindollar R, Reddy RK, Wright TL, Lin A, Hoffman J, De Pamphilis J: Peginterferon alfa-2a in patients with chronic hepatitis C and cirrhosis. N EnglJ Med 2000, 343:1673-1680

\footnotetext{
Publish with BioMed Central and every scientist can read your work free of charge

"BioMedcentral will be the most significant development for disseminating the results of biomedical research in our lifetime." Paul Nurse, Director-General, Imperial Cancer Research Fund

Publish with BMC and your research papers will be:

- available free of charge to the entire biomedical community

- peer reviewed and published immediately upon acceptance

- cited in PubMed and archived on PubMed Central

- yours - you keep the copyright 